him. I expected to find exostoses afterward, but there was none nor any pressure symptoms, and the man has never had a fit since.

Dr. LAPlace-I am glad that one speaker found serious objection to my paper and especially as to the mortality. I hope no one misunderstood me. Two per cent. mortality is based upon giving surgery a show. My only object has been to put the matter in a clear light before the profession. Later it will be shown whether children are able to withstand a certain amount of shock. As I explained in my paper, I tried to stay on this side of the line of reason. When I find an operation too grave I stop there and, acting on this fact, I wish to say that there is no earthly reason why the mortality should be more than 2 per cent. If there is, it is the fault of the surgeon. As to drainage, let me say that, granted there is a certain amount of contusion, there is autocompression of that brain and opening the dura will necessarily relieveit. I think you will all agree with me in this, that when the dura is opened the cerebral fluid spurts out. In these cases the patient will become conscious in a few hours. I do believe that such an extensive craniectomy, accompanied by an incision into the dura, will relieve to a certain extent the whole of the brain, but more especially the anterior portion, as it is generally in these cases that unconsciousness exists. As to cases of arrested development, I thought I made my position clear. I admitted that the operation was impractical, and I do it because I hope to have some consultation on the theory of counter-irritation. Dr. White knows that there are cases in which improvement follows and we know not why. Why may this not be one of those classes? We all know how in cases of abdominal surgery today there is no hesitation in exploring the cavity, and if things are all right it is closed up, but if not all the conditions present are attended to. I am glad that one man spoke in the way he did. We must be very careful in doing this work, but we should not be backward. We know all about hemostats and antisepsis, and we can adopt both if we need them. Finally, in trephining over temporal fossa I go through the thickness of the skull, but not through the inner table if I can help it, as I prefer to break this off with the chisel. The middle meningeal artery runs through the skull in many places and, therefore, it is unwise to trephine directly through the whole thickness of the skull. I have an instrument with which I separate the adhesions and it is particularly useful for this purpose over the longitudinal sinus. I run this instrument all over the surface of the dura and pass it all around the opening, completely separating the adhesions. The instrument is no larger than an ordinary wire, and it has the advantage of not tearing the tissue at any time. Beginning at the superior longitudinal sinus I plunge my knife directly down the surface of the brain, and you would be surprised to find how the cerebral fluid comes out. There is no danger of hernia, as the opening is not large enough for the brain to protrude. I use T-forceps for this special purpose, and not more than one ounce of blood is lost. I proceed to pack, after having opened the dura, with fresh sterilized gauze. Ordinarily I do not use iodoform gauze in the brain, but under somecircumstances itdoes very well. Some brains have a strange idiosyncrasy against iodoform and it will start up an irritation there which will be very prone to become septic. I therefore simply use dried gauze sterilized, and I apply two pieces to drain, packing them well into the groove I have made. I grad ually remove the forceps and apply my sutures. There is no shock, and practically no loss of blood, although some of you might be disposed to doubt that. When I first began to operate I did not do it in the way I do now and I did not succeed in my early operations as I do now. We must not consider these operations lightly by any means, and we must not operate on the brain promiscuously. All cases that are operable should be operated on by those who know how to operate, and there is practically no difficulty in removing the cause.

Dr. CRYER-Dr. Wyman questions how the instruments operated by the engine will work upon living bone. It works quite as well upon living as upon dead bone; the tools do not become clogged or choked, nor do they become heated, provided the cutting tools used are made especially for the type of bone to be operated upon. Heretofore the cutting tools were made without sufficient regard to this particular; as a rule they had too many blades which were of equal size. You will observe these tools have three blades differing slightly in size; this prevents chattering or vibration of the tool, and they are self-cleansing. The subject which I have used for demonstration has been dead but three days, and the texture of the bones is almost the same as in the living subject; to be sure there is no blood flow, but the cutting under blood interferes with operations only in so far as it obscures the view of the territory.

\section{ACUTE PARTIAL ENTEROCELE.}

Presented to the Section on Surgery and Anatomy, at the Forty-eighth Annual Meeting of the American Medical Association at Philadelphia, Pa., June 1-4, 1897.

BY FRANK A. STAHL, M.D.

DEMONSTRATOR OF OBSTETRICS, RUSH MEDICAL COLLEGE; EX-INTERNE ROYAL FRAUENKLINIK. MUNICH. CHICAGO.

Herniæ involving only a portion of the circumference of the bowel, and usually spoken of as Littre's herniæ, are of two forms: One is a diverticular hernia, a hernia where a diverticulum of the bowel forms the contents of the hernial sac; the other is the partial intestinal wall hernia, partial, lateral enterocele (enterocele partialis seu lateralis seu hemiperipherica), where only a segment of the free margin of the bowel forms the contents of the hernial sac. Partial intestinal wall herniæ occur in two forms: The acute partial enterocele, where the hernia is of sudden origin and without adhesions; the chronic partial enterocele, where the hernia is of slow origin and usually with adhesions; that the acute form occurs is denied. Clinical experience alone can refute this denial, and the material is not lacking that will constitute the necessary burden of proof to establish the fact that acute partial enterocele occurs; it is in this spirit that the writer has been led to present the following clinical manifestations.

In 1891 I reported a case of acute partial intestinal wall hernia occurring in the sac of a previously existing incomplete inguinal hernia.

The peculiar symptoms in this case were: 1 . Absence of any tumor, slight redness of skin over point of rupture. 2. Pain commencing at and returning to a point marking the place of exit of previous hernia. 3. Patient had two loose stools, which caused increase of pain at the seat of stricture. 4. Continued retching, but no vomiting. 5. Just before surgical anesthesia was reached in attempting to reduce by taxis I was able to appreciate a sensation like that of drawing upon something immediately above the seat of previous hernia, having a fixed extremity and which, as the anesthesia became more profound and traction was continued, gave way little by little. Traction being further continued a slipping like that of this something being suddenly released was experienced.

Case $1 .^{1}$ - A record of the case is as follows: Male, 28 years of age, weight 145 pounds, height five feet seven inches, nervous temperament, wood-turner by trade, required to stand most of the time; no record of abdominal traumatism previous to primary occurrence of a year ago, when I was sent for and found a strangulated incomplete inguinal hernia of the right side, which was soon reduced after using hot fomentations and taxis. Truss applied; continued his work the next day. Patient went to work in the morning feeling as well as usual, the truss retaining the gut. During the morning he did some lifting. Soon after the lifting he noticed, while standing at his bench, a slight pain at the place of rupture. The pain continuing, he examined the part, but could find no tumor, so thought nothing more of it, and continued his work. As morning wore on, noticed that the longer he worked the more intense became the pains, bowels moved once during the morning. During dinner-hour, getting an opportunity to lie down he did so, the pains relaxing somewhat, not wholly. Soon after commencing work the pains reappeared with increased severity, but now taking on a different nature. His bowels rolling, commencing at the point of rupture, continuing to the pit of the stomach, returning again to the starting point. Bowels moved (loose stool again during the afternoon with slight momentary exacerbation of pain at the point of seizure. Notwithstanding the intense nature of the pain he continued working, finished with the others and made his way home, walking part of the way. Arriving there he complained of dizziness from the pain and exertion, still he did not lose consciousness. Thinking that if he would lie down awhile the cramps would cease he went to 
bed. His condition not improving, rather continuing to grow worse, word was sent me.

Examination found the patient lying on his side with limbs fully flexed, hands holding abdomen; face presented that anxiuus, pinched expression peculiar to peritoneal trouble; skin bot covered with perspiration; resuiration and pulse slightly increased; continued retching but no vomiting pres. ent; no tumor at point of rupture ; skin covering it slightly reddened. Pains were of sharp lancinating character, conmencing at the point of rupture and extending to the pit of the stomach. Patient showed tenderness at only these two points. Percussion showed marked meteorismus. Recalling my experience with previous hernia I immediately thought of a strangulated hernia of a small part of the circumference of the bowel; still the probability of a peritonitis also presented itself. Applied hot fomentations, and administered morphin per stnmach, one grain in divided doses within half an hour. Instead of affording relief, the pains continued to grow, so ruled out the peritonitis and adbered to my first impression of strangulated partial hernia. The wife, as on a previous ocea. sion, requested me not to operate unless absolutely necessary, so I administered chloroform, preparatory to trying taxis. With one hand below the point of rupture, the other above, I, alternately nushed with the one band, made downward and upward pressure with the other upon the abdominal walls with contents beneath. The latter movement produces trac tion. Continuing the traction, I was able to aprereciate the sensation as of drawing upon something beneath my fingers and within the cavity whose other end was fixed. The narco sis becoming more profound I continued to make traction, and was soon to my delight rewarded with a sudden slipring upward of the hand niaking traction, confequent upon the extremity of this something being suddenly released.

As mentioned above 1 bad already administered a grain of morphin before giving the chloroform. Before the reduction, if the chloroform was not pushed, the patient soon rillied. After the reduction, though the chloroform was immediately removed, patient did not rally but continued sleeping, bis face now presenting a less pinched arpearance, his respiration becoming slower, also his pulse. Remaining yet a little while noticing his inproved condition continuing, I left, leaving instructions to let him continue sleeping.

Directed to take a bottle of citrate of magnesium and teaspoonful of mixture containing $1 / 4$ grain of morphin every four hours and coft diet. Next morning patient was up and about. When having a movement of the bowels the next morning, after taking citrate of magnesium, and also an enema, pain was caused in the region of the cecum only, the patient expressing hiniself as follows: 'My bowels pain me in one spot only while I am having a passage, otherwise I have no yain." Trufs was applied and the third day after occurrence patient was able to return to work.

In the discussion several expressions of doubt found utterunce as to the correctness of the diagnosis, one thinking the case had been one of omental her. nia; anuther thought the casa one of simple invagi. nation of the bowel. The history of an acute epiploitis arising from an acute hernia differs very materially from the above. Professor N. Senn, in the course of his remarks said: "A Littre hernia is a hernia that is exceedingly dangerous. It is a hernia that contrins only a part of the circumference of the bowel. The hernial ring being very small and the contents of the hernial sac being limited, gangrene takes place in a very short time. I hardly think that by ordinury care it would be possible to confuse invagination with Littre's hernia, berause in Littre's hernia at least a slight external swelling can be detected, the swelling occupying a position where we expect to find the different lierniæ. The writer has informed us that in the last case he suspected that the Littre hernia followed as a secondary condition of a former woll marked hernia, and therefore I have no doubt that it may have been a Littre hernia which was reduced before signs of strangulation occurred."

At the time I reported my case I had not met with Lorenz, "Ueber die Durmwandbrüche," 2 else I might have presented another case very similar to mine in many respects (though more severe in degree), both in the history of the anamnesis, symptoms and signs, and in the anatomic relation of the parts involved.

The case presented itself for operution in Professor Albert's clinic. From the previous listory of the case, it seemed like mine, one where secondarily an acute incarceration of a segment of the bowel with strangulution was manifesting itself, in a previously existing hernial sac.

That such a phenomenon could occur had been up to this time (1<83) a mooted question. Therefore, in performing the operation it was done with this epecial problem in mind: Do acute intestinal hernia occur into a previously existing hernial sac or, in other words, cun an intestinal wall segment suddenly enter a congenital, or a more or less longer existing hernial sac und immediately become incarcerated.

The findings of the case under operation were such that Lorenz presented a history of it, showing and to prove, that a bowel segment can and does become so incarceruted.

Case 2.2- A well developed boy, 16 years of age, slight in fig. ure and healthy appearance, when seven years of age (1874) was directed to wear a truss for a right inguinal hernia. He continued to wear the truss for several years. In the course of time, the truss becoming too small, he laid it aside until the iresent occurrence, September 1883, without complaining of any disc mfort. Sept. 11, 1883, while he was carrying wood, he was suddenly taken with abdominal pains and vomited twice in succession. Immedrately palpating the addominal walls the boy discovered a small tumor in the right inguinal region. Vomiting continued during the night. Septenter 12 , bry feels comparatively. well. Afier unsuccessful attempts being made, by a j, bician, to reduce the hernia, the patient entered the clinic that evening.. With the exception of an active thirst the patient presents no otber symptoms. After drinking immoderate quantities of water he romited once toward evening and once during the following night. An attempt at stool was almost without result.

September 13. With the exception of drawing pains in the abdomen patient feels well. Flatulency, none since the csitical evening, the facial expression is normal; the pulse full and strong; cuntinuı us thirst. A bdomen Hat, very slightly sensitive to palpation. In the right hypogastrium ulon deep and brueque palfation seneation elightly greater, but there is not the least resemblance to the intense pain usual at the neck in bernial strangulation.

Operatim : Cutting down, opened sac from which there flowed, rop ortionately sl eaking, a large quantity of a hemor rhagic colored fluid. The whole tunior seemed to melt away entirely ; found a blue, red appearing, swollen part of the intestine; no trace of omentum; no adbesions between bowel wall and hernial sac. Because of the small size of the bowel segment the possibility of a partial enterucele presented itself, and to determine the question the greatest care possible was exercised in the furtber dissection of the parts. A t the internal inguinal ring a conical portion of the intestinal wall was found incarcerated : the structure was divided and a considerable portion of the intestine drawn out to demonstrate that the mesenteric border of the gut presented absolutely no changes upon its superficies, and was of normal red color, while upon its convex border there appeared the well marked strangula tion furrow, that lookely encircled a yrotruding intestinal wall seyment. The gut was replaced; wound dressed to favor union by granulation: toward evening much flatulency. The night was passed without pain and sleeping most of the time.

September 14. Wound dressed; looking well; ; aldomen soft and painless; flatulency continues. General condition good.

St ptember 15 and 16 . In the night two bowel movements, profuse ind soft. Condition continues good. Recovery followed without anything of note occurring.

Again there are exceptional cases where the symptoms and signs point to incarceration with strangulation, yet herniotomy determines only an empty hernial suc with subsequent cessation of symptoms. Here it would seem that a small segment of the bowel had been incarcerated, strangulation with its munifestations following; primary attempts at reduction with taxis are made; they fail; the anesthetic is hurried; 
the narcosis may induce relaxation of the spasmodically contracted hernial orifice; reduction may succeed as in my first case (1891), or this happy result may not be induced until herniotomy with opening of the sac occurs, and then only to find no intestine. In this latter cuse undoubtedly at some time during the narcosis or herniotomy there was reluxation of the spasmodically contracted hernial orifice sufficient to release its grip upon the segment of the bowel wall; the bowel would then retract within the abdominal cavity.

In dwelling upon this feature of this form of hernia Lorenz mentioned such a case where operation was necessary, that developed only a hernial sac but no intestine.

Case 3.2-Moderately well developed but strong woman. Four months ago she noticed a small prominence in the left groin, upon the advice of a friend, wore an improperly fitting truss, which she soon laid aside. September 11, in an argument with a friend, she received a kick in the region of the lower abdomen. From this moment she complained of strong abdominal pains and repaired to the Polizeiartz. He rendered a negative opinion and quieted the woman, who, notwithstanding, trok to bed. During the night she experienced beartburn, belching, retching and profuse vomiting three times. The patient dis covered a nut sized elastic tumor in the left groin. Calling upon the Bezirlesartz, he diagnosed a hernia and advised in mediate re moval to the hospital. During the night of Septem ber 12 and 13 patient applied cold compresses, and during this time was disturbed by continuous belching and retching. Passed restless night, appetite lost. As her condition did not improve she permitted herself to be taken to the hospital where fur four hours she was closely observed. Luring this time there was continuous retching, yet no vomiting. No flatu lency for three days, and though, to ease ber condition, patient reveatedly attempted to stool, her efforts remained unsuccessful. At the time of ber admission patient presented the ap pearance of one seriously sick, complaining of great weakness and aldon ind y ains, true collape not present. In the left groin, a pigeon-egg sized, firm, hollow, percussionable tumor, covered with normal integument, which accurately indicates a left femoral hernia. Ahdumen moderately tympanitic and excessively sensitive. Palprating the hernia and sac, patient contracts because of intense pain. A ttempts at taxis in warm bath without result. Patient narcotized, taxis repeated unsuc cessfully ; hernicitomy.

After careful division and drawing apart of the hernial sac there was nothing to be seen of an intestinum. It is impossi ble to advance the tip of little finger in the direction of the femrral ring. After repeated attempts, a strong sound was introduced several inches in the direction of the abdomina cavity. The sound completely obstructed the unusually small hernial sac; therefore, the presence of an incarceration was ruled out. Sac extirnated, tied, wound closed, continuous with the narcosis, patient fell into a sleep and awoke late in the evening without abdominal pain and retching. 'The next day fiatulency. Not until the third day did the bouels move and then profusely following two clysmata. Wound bealed with first intention. On the second day appetite reappeared and patient considered as convalescent.

In regard to this case, taking into account that when the hernial sac wis opened there appeared but a transparent clear serous fluid and that there existed a three-days impermeability of the bowels, the probability must be thought of that through the narrow hernial orifice a bowel segment had been invaginated, which, however, had withdrawn itself even before the operation. Lorenz does not even attempt to question that the invaginated intestinal segment can withdraw itself again.

Unless relieved, what happens in such a case of neglected incurceration of an acute partial enterocele?

1. Symptoms of strungulation follow, with inflammatory changes. If the inflammatory processes be too active for the powers of the general system, then follow gangrene, sloughing, perfurution, artificial anus, exhaustion and death, in rapid succession. While preparing this paper Dr. Robinson informed me of such a case having occurred just recently in the luands of a country pructitioner. "The tissues were incised down to the gut, which was left to slough. A segment of the bowel wall, directly opposite to its mesenteric attachment, was caught in the hernial ring. At first gas passed from it for several days. On the fifth day after the first incision a laparotomy and a bowel resection with a Murphy button, was performed. Death resulted from sepsis."

2. The system countenancing the reactionary processes induced by the incarceration, strangulation does not occur, adhesions set in and the acute condition gradually merges into one of chronic partial enterocele. Like changes may and do occur in old herniæ; a spot inflames and becomes adherent, and though at times the greater mass of bowel spontaneously returns within the abdominal cavity, a small segment of the wall still remains hernial, bound down by its adhesions. Since the bowel lumen is only slightly disturbed. the feces pass with little or no truuble, the general system soon adapts itself to the new condition of things and exists an indefinite length of time in this state until an acute exacerbation compels relief or ushers in death.

Such was the history of my second case, which is quite typical of these cases of chronic partiul enterocele.

In August 1896, I was called to see a woman, aged 60 years, who had already been confined to bed some ten days before I saw her. She was of medium development, fuirly strong, but tissues quite flabby. There was no history of previous hernia. Four years ago she suddenly noticed a small swelling in the right groin. She did not know how long it had been there as its appearnnce was not the result of any known cause; neither was it marked by any of the symptoms usual in acute hernia. The swelling would disappear and reappear, seldom producing any protracted serious discomfort, more than that of a day or several days at the most. At these times she would complain of pain at the site of the swelling. and anorexia and constjpation. This was attributed to exertion, catching cold, with colicky puins and acute constipation, for which her physician advised rest, and administered, among uther therapeutics, much of a cathartic nature. Hernia was thought of, but becruse of small size and transitory appearance of the swelling his opinion inclined to a glandular swelling with occasional inflammatory reaction.

Some ten days ago, while beating carpets, in lifting a piece over the line, patient was suddenly seized with a sharp pain at the site of the swelling; palpating the parts noticed, the swelling had increased in size and was now tender to the touch, and she went to bed. Reflex symptoms, as belching, retching and colicky pains, soon manifested themselves. Her attending physician administered a medical acute intestinal obstruction treatment, with opiates for pain, lime water, etc., for vomiting, and various cathartics with repeuted clysmata for the non-bowel movement. For some days no attention had been shown the swelling. When attention was called to the swelling from the inflammatory picture it presented, a probable suppuration of an inguinal glund was thought of, complicating the acute obstruction. Poultices were ordered applied. Her family physician calling in a friend, the consultution determined in the order of their imporfance, a suppuration of a gland, a possible perinephritic abscess und a possible gangrenous hernia, with indications for immediate operation. The next day, being invited to see the case, examination revealed a reddened, inflamed, firm oblong mass along and over 
the right Poupart's ligament, and continuing down into the right labium.

Palpation.-Tenderness which spreads out toward and over cecal region, superficial and deep fluctuation with crepitation, as though there was gas in the tissues.

Percussion.-Over swelling gave suppressed, deep sounding hollow note. Abdomen sensitive only as the region close to the suppurating mass was ap. proached; tympanitis not marked. General symptoms, expression, etc., were indicative of a local peritonitis with gangrene from hernia. For a week no bowel movements, anorexia, retching, vomiting and slight increase of pulse and temperature.

My diagnosis was strangulation of an acute exacerbation of a chronic partial enterocele al the right femoral ring with gangrene, perforation and septic perforating cellulitis.

Cutting down upon the mass a profuse ichorous discharge was liberated, in which was noticed pus, necrosed tissue, gases and feces. Many pocket-like sacs were opened up in the surrounding areolar tissue, containing a like ichorous material. With continued irrigation the field was finally cleared of ichor, feces and débris. Deep down and above in the femoral canal I found a gangrenous bowel with perforation, through which at first passed much gas and some feces. Simultaneously the slight abdominal tympanites disappeared. Upon one side the bowel was bound down by adhesions, upon the other side it was free, and careful examination seemed to show that there was only a part of the circumference of the bowel at that point in the hernial ring.

I confined my examination to inspection only, as I thought it better to wait forty-eight hours before resecting the bowel, in order that in that time the bowels might have opportunity to thoroughly empty themselves and the inflammatory reaction abate. The wound was dressed with absorbent cotton.

Patient reacted beautifully, citrate of magnesium only was administered. During the night, late, the upper bowel moved repeatedly and profusely through the artificial anus; there were also two movements through the natural anus. I attributed these two movements to the inflammatory reaction caused by the operation, and due to which there must have been a strong intestinal secretion throughout, causing two loose movements. These must have been from the more lower bowel, as two days afterward the rectum was again found full of dry scybalæ.

Frequent dressings were given during the fortyeight hours. The wound looked clean and healthy, and the symptoms abated very materially. The lower bowels were emptied, so far as possible, by means of clysmata. Secondary operation was performed for resection of the bowel and closure of artificial anus. The adhesions were broken down with the tip of the finger, the bowel drawn out and resection performed. I did not use a Murphy button, fearing its nonpassage through the lower partially collapsed bowel; bowels returned, wound dressed; no shock, no collapse. Next day she conversed, with smiling face. Two days after operation the patient died. There were little symptoms of peritonitis present, her pains were very. slight considering the operation and that no opiates were used, and death seemed due to gradual exhaustion.

Through the kindness of Dr. Geo. H. Weaver of the Pathologic Institute of Rush Medical College, a report of the findings in the specimen is as follows: The specimen consists of a portion of small intestine, about $5 \mathrm{~cm}$. long on either side of a defect in the wall. The upper portion is $3 \mathrm{~cm}$. in diameter, the lower $1.5 \mathrm{~cm}$. The wall of the upper portion is thicker than that of the lower. On the free border of the intestine near the middle of the section is a conical projection $2.5 \mathrm{~cm}$. in height and $2 \mathrm{~cm}$. in diameter at its base.

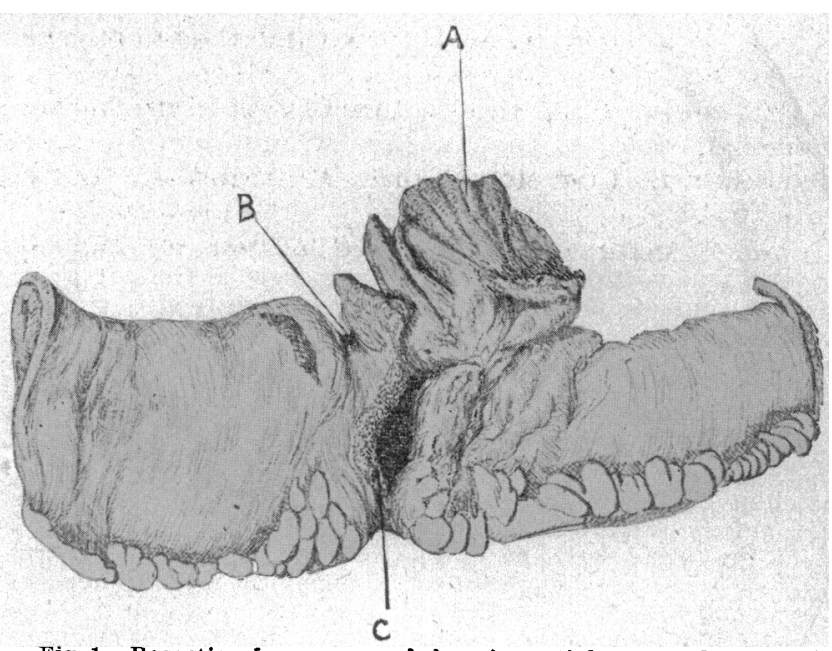

Fig. 1.-Resection from a case of chronic partial enterocele-chronic Littre's hernia-with acute exacerbation, showing: a, acquired diver

The outer surface of the projection is uneven from the presence of dense fibrous bands and masses. About its base on its outer aspect is a circular groove fairly well defined. The serosa of the intestine is continuous with the outer surface of the projection. This projection is located to the lower side of the point of gangrene in the intestinal wall, to be described below.

On section through the cone, from apex to base, its walls are seen to be continuous with those of the intestine and to be made up of a fibrous layer externally continuous with the intestinal serosa (Fig. 2, C), a muscular layer (Fig. 2, B) continuous with the intestinal musculosa, and an internal coat continuous with the mucosa of the intestine (Fig. 2, A). The projection internally is occupied by a cavity opening into the lumen of the intestine.

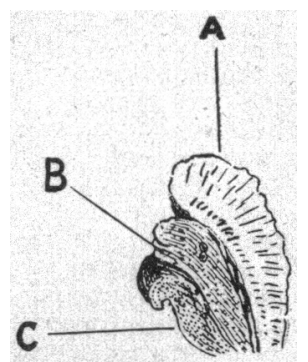

Fig. 2.- Section of the diverticulum from apex to base, showing the inteatinal layers: $a$, mucosa ; $b$, musculosa; $c$, serosa.

Microscopic examination of a section of the wall of the projection shows that all the coats of the intes. tine are continued across its whole height, muscular and mucous coats being present.

The wall of the intestine is defective from a gangrenous process on one side just above the projection above described (Fig. 1, C). At both ends of the gangrenous defect are well-marked grooves in the outer aspect of the intestine, both at the free border and at the mesenteric attachment, running at about 
right angles to the lumen (Fig. 1, B). This evidently indicates the line of application of the body causing the obstruction and gangrene.

In referring to the parts of the intestine they have been spoken of as upper and lower portions. The

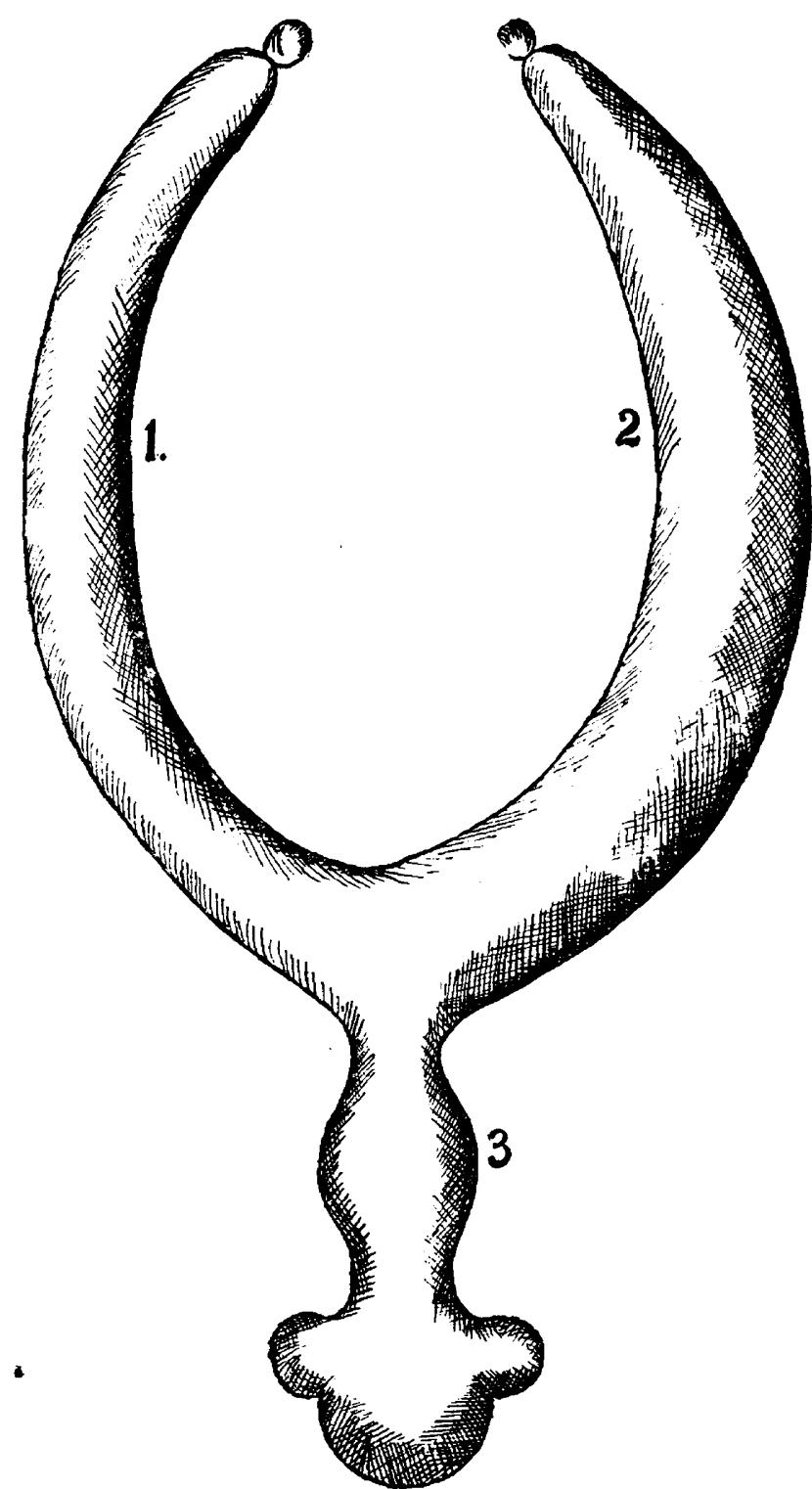

Fig. 3.-Illustration from Littre's first case, 1699. A Meckel's diverticulum found hernial in the left inguinal ring and canal. 1 , Partie de l'lléon du côté de l'anus. 2, Partie de l'ileón du côté de l'estomac. 3, Appendice de l'intestin iléon.

Tne congenttal diverticulum, Meckel's diverticulum verum, is a dilatation of the small intestine, representing a hollow appendix, which consists of all the intestinal membranes, and is placed at from eighteen to twenty-four inches from the cecal valve; although we do not quite assent to Meckel's view, that it is a remnant of the umbilical canal, it evidently has its origin in the development of the intestine in the umbilical vesicle. It accordingly is found solitary and attached at the above mentioned spot; it varies in length from five to six inches; it sometimes is wider, sometimes narrower than the intestine itself; it is frequently contracted at intervals of a conical or cylindrical shape and terminating in a round, clubbed or lobulated expansion. It either projects at right angles from the convex surface of the intestine, hang ing unatta the concave surface of the intestine near the mesenteric insertion, being attache to the latter by a lalciform process of the peritoneum. In thi case it is often placed parallel to the intestine. Occasionally a liga mentous cord, the remains of the omphalo-meseraic vessels, is found at its free extremity, and as this may, by its adhesions to various points the intestine), it receives importance in a pathognomonic view.- RozITANSKY.

larger portion had evidently been dilated and hypertrophied because of its location above the point of obstruction, and the smaller portion contracted because below this point.
The specimen shows then the following conditions: A Littre's hernia of long standing, as evidenced by the old, firm adhesions about its base and outer surface of the button, and a gangrene of the wall of the intestine from an obstruction by pressure of recent occurrence.

Through the courtesy of the superintendent of the National Library of Paris, I have received a copy of the illustration, by Littre, of the part of the bowel and the diverticulum involved in his first case of hernia (Fig. 3).

I introduce the illustration here, the better to bring out the difference between a chronic congenital diver. ticular hernia and a chronic intestinal wall hernia, both being regarded as Littre's hernia; Littre's first case having been one of chronic diverticular hernia and his second one of chronic partial enterocele.

In reviewing my second case, I think four years ago there was an acute partial enterocele. At various times local peritonitis developed, resulting in the profuse adhesions with fixation of the bowel segment forming the primary,acute partial enterocele, thus the acute partial enterocele gradually developed into chronic partial enterocele.

\section{RETROSPECTION.}

That the chronic form of partial intestinal wall hernia occurs is admitted by all, but not so that of the acute form. That the acute form of partial intestinal wall hernia occurs is still denied by authorities of note of today, among them Koenig.

This seems in a great measure to be due to the negative results obtained by Roser, ${ }^{3}$ who in 1859 pub. lished the results of his experiments upon the cadaver with regard to this special form of hernia. Because he was unable, first, to apply a ligature laterally to the circumference of the bowel; and second, when he drew a segment of the bowel through a hernial orifice, the segment would not remain fixed, his conclusions led him to deny the occurrence of a free marginal segmental hernia. From 1859 to 1883, Roser's denial seems to have quite thoroughly saturated surgical atmospheres.

In 1883 two cases presented themselves for operation in Professor Albert's clinic. Both proved to be cases of incarcerated acute partial enterocele without adhesions. The first was a partial intestinal wall hernia of the small intestine incarcerated in the left femoral ring. The second was a partial hernia of the large intestine incarcerated at the right femoral ring.

Case 4.2-Woman aged 50, quite marasmic. On the right side there has existed a femoral hernia for some years, successfully retained by truss. On the left side patient until three days ago never noticed a swelling. On the first day, without any known cause, she was taken with strong pains in the abdomen. retching, shortly after vomiting. Physician recognized a left femoral hernia. Upon the third day of incarceration patient was sent to the clinic for radical operation. Here was recognized a walnut-sized, firm, immovable irreducible swelling under Poupart's ligament of the left side. Continued vomiting until slight collapse and rapid pulse; no bowel movement for three days. Immediate operation. Cutting down, scraping through the hernial sac, there was found a dark blue, very congested intestinal pouch closely lining the inner surface of the sac, though nowhere adherent with it. The pouch presented the appearance of a large cherry of a bullet form. No adhesions. Drawing out the bowel, it proved to be small intestine. The compression ring occupied the convex side of the loop and surrounded as a circle a dark blue projecting intestinal pouch. The pouch did not undergo any organic changes, as in rolling out the intestines the pouch disappeared quite completely, so that the convex margin of the loop showed two slight compression rings, marking only a flattened protuberance. No change日 in the mesenteric margin whatever; bowel replaced; wound 
packed; union by second intention granulation. Flatus passed the same day; second day after operation profuse bowel movement. No more vomiting was noticed. Left the huspital on the eighteenth day.

Case 5.- Well developed male, potator, aged 41. Messenger carrier. Patient says he never had a hernia or even a swelling in inguinal region. Wounded in chest at Koeniggratz in 1866; discharged cured. Always enjoyed the best of health since, Regular and easy stools without assistance; never complained of indigestion.

February 19, 1882. With an assistant be lifted two 2 centner iron cares into a railroad car. During this exertion be felt in the right lower abdominal region a sharp pain, followed by strong colicky pains. On this account two hours later be took to bed, and noticed for the first time an egg sized tumor in the right groin, wbich be painted with tiveture of iodin. The abdominal pains continued and caused a sleepless night.

February 20. In the morning he vomited once. Phy sician advised patient to go to the hospital, but advice not heeded. Pains continued, anorexia complete. This condition continued several days, during which his general condition was in proved, though the local tumor increased considerably: non-bowe movement for two days, then patient relieved with a senna decoction. Meanwhile patient consulted a second physician, who advised immediate removal to the hospital. The vomiting had not been repeated, though there had been a transitory tendency thr reto.

February 22. Entered clinic. Swelling size of a man's fist in the right groin, covered with integument so stretched that it can not be folded, and of a dark red color. lts relation to the inguinal or femoral canal can not be given with certainty because of the dense peripheral infiltration. Consistency elas tic. Deep ind istinet fluctuation; percussion note hollow toward the hypogastrium; upon stronger percussion, tympanites with similir sound from the abdomen. Abdomen soft, not painful upon pressure ; pains ceased. The general condition of patient soems not to have been seriously disturbed. Pulse 76 , full and strong; tongue moist; face unchanged, with expression of a serious affection; slight rise in temperature. During the first day of the clinical ohservation the bowels moved profusely three times. The colicky $\mathrm{J}_{\mathrm{ain}}$ had ceased, vomiting bad not occurred again: patient complained only of want of appetite.

Notwithstanding the local picture, which was typical of a gangrenous hernia, the possibility could not be overlookt $d$ that the statements of the patient, especially as to the rapid occur rence and growth of the questionable tumor, might be hased upon an error, and that possibly but an adenitis suppurativa presented.

February 23. Four days after its commencement, operation undertaken by Professor Alvert. While waiting in anteroom patient had another bowel movement of watery consistency; walked to the operating table. ('peration. Cutting down carefully until the non-adhering bowel could be drawn out, which was found to be large intestine (cecum). Exanination revealed that from the anterior margin (convex) in the vicin. ity of the ceco-ileac articulation a segment of the intestinal wall was incarcerated in the right femoral ring. The segnent projected somewhat; the deeper organic changes, as suggillation, and in spots commencing gangrene (though no perforation), ceased at the base of the pouch. Death during the night of the fourth day in the hospital.

Just here I might add a case of Littre's hernia reported by Dr. J. C. Oliver, ${ }^{4}$ Judging from his history of the cuse it would appear to have been one of acute incarceration of a segment of the bowel wall. His report of the case is as follows:

Case 6.-German woman, aged 33. Close inside the left spine of the pubes a small lump about the size and shape of a shellbark hickory nut, free from pain and tendern'ss. The impression given to the fingers was that of an evlarged inguinal gland. Operation revealed a small sac about the size of a hickory nut, which was laid open. It was found that a small kouckle of the intestine was caught in the external abdominal ring. The stricture was tight, and was notched with the herniotomy knife. The entire lumen of the bowel had not passed through the ring, only a portion of the circum ference being engaged where the sac was opened. After fifteen minutes application of warm towels to re establish circulation, the knuckle of the intestine was returned into the abduminal cavity, wound sewed up and dreseed. Bowels moved once during the night. Perfect union by first intention followed.

Dr. O. said when the case was first seen, I was inclined to think we were dealing with an enlarged gland, the diagnosis of the hernia being made at the operation. It was then found to be of the direct inguinal variety and that but part of the circumference was caught in the ring. A majority of the cases of Littre's hernia have been of the femoral variety, this being a direct inguinal hernia adds decidedly to jts interest. (Cincinnati Lancet-Clinic, Vol. 35, p. 63, July, 1895.)

The two former cases seem to have prompted Adolf Lorenz, an assistant to Professor Albert, to a further and critical study of this unsettled question. His "Ueber die Darmwandbu üche," 1883, is the fruit of his investigations and observations in this direction.

In his introductory, he writes that "on some sides this latter form of hernia, enterocele lateralis seu partialis acuta, is toduy still opposed by un unwarrantuble doubt, but which is rooted especially in theoretic speculation."

Thus, B. Schmidt ${ }^{5}$ had expressed himself but a few years before: "It is cluimed that at times only a segment of the free circumference of the bowel, opposite the mesenteric altachment, protrudes into a hernia. Until the bowel wall is found not adbering in the hernial sac or in its orifice, I must join with those who deny this form of hernia. (Roser, and others). A free intestinal wall hernia I have never seen, and know of none in the literature."

Lorenz's reply to these theoretic objections was the following record of a judicial postmortem made by an officer of the Vienna Health Department. "A four months, male infant, well developed, $67 \mathrm{~cm}$. in length The free margin of an intestinal loop situ. ated about a meter from the ileo-cecal valve, protrudes quite loosely into a small sized umbilical stic lined by thickened, in places, gray pigmented peritoneum. In the intestine much gas and bile, colored soft contents. . . It is not difficult to understand how, though the capacity of the sac be too small, to lodge an entire loop, yet it may not be too small to temporarily lodge a part of the intestinal wall." Notwithstanding the clinical and postmortem evidence furnished by these cases, fucts meeting even the extreme theoretic objections insisted upon by Roser and Schmidt, today there yet exists doubt that acute partial intestinal wull hernia occurs, which is all the more unfortunate in that it has a tendency, as reference to the reports of these cases will show, to throw the inexperienced off his guard when encountering this dangerous and usually well masked form of hernia.

Albert, ${ }^{6}$ in his "Chirurgie," which appeared a year later (1884) than Lorenz's monograph, writes that "even though seldom a small segment only of the bowel may present." Nevertheless, Koenig, ${ }^{7}$ also a standard of today, in his latest edition of 18:14, seems still to adbere to the opinion he expressed in his earlier editions (1883), numely, 'Wo deny. and least of all upon the evirlence of the sections offered till now, that one is justified in accepting the existence of an acute arising incirceration of a small not previously pouch-like formed segment of a bowel."

In view of the evidence as furnished by the clinical manifestations seen in the cases reported above, and not forgetting that the operations in cases 4 and 5 were performed by no less distinguished a surgeon than Professor Albert, with observations made under his personal supervision, with faithful histories of the cases and with faithful descriptions of the anutomic and pathologic conditions encountered, he who would not believe such evidence must surely be a doubing Thomas; to say the least, if there be any question, it seems to $m e$ it is one of veracity rather thun of fact. 
Argument of theory is never so powerful as presentation of fact, and I am willing here to venture to weigh the "brute force" of clinicul experience against the ephemeral force of pleasant speculation, and entertain no doubt as to the direction of the inclination of the pendulum.

Again, througb the courtesy of Dr. Robinson, I am enabled to present another clinical manifestation of the bowel; which will materially assist in comprehending this question. In explanation of a new theory for the causes of hernia, he presents the following: $:^{8}$

"Irregular action of the gut.wall is the one cause which I wish to add, and one which I have not noticed in the books nor heard discussed. I gained the knowledge from the abdominal drain-tube. In laparotomy 1 use an aluminum drain-tube perforated by quite small holes. The holes are only about half as large as those in Keith's glass drain-tube. The holes are so small that one can not push a piece of bowel into one. Now, in a series of 100 laparotomies,

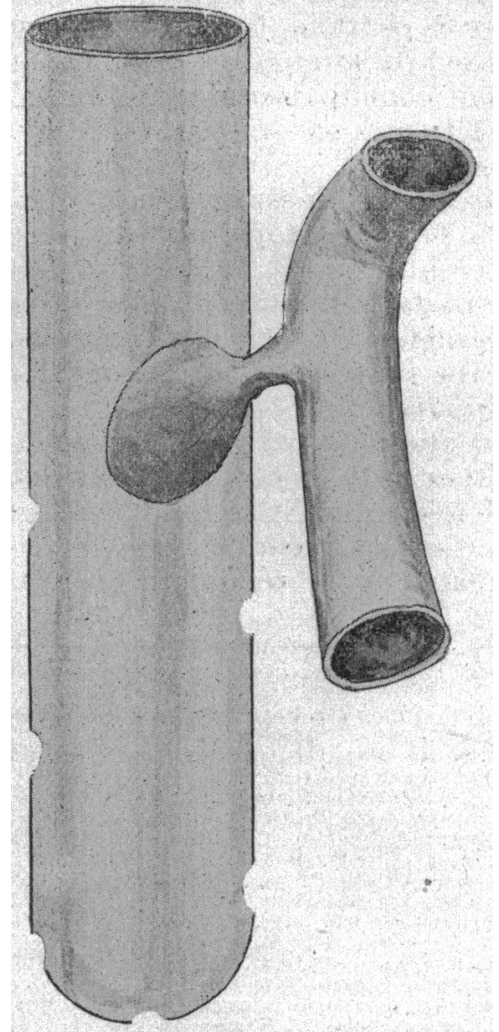

Fig. 4.-Showing irr.gular action of the howel causing invagination of a segment of the howel wall inio opening in keith's drain tube; ticulum. (Drawn by Dr. Robinsou from on of his ases uperated upon for uppendicitis.)

Dr. Waite and myself have had three cases where the gut-wall had penetrated these small holes in the side of the drain-tube. We were obliged to steadily pull the tube upward and then tie the bowel wall with a ligature."

[In this case Dr. Robinson, having such a bowel possibility in mind, had left word with the nurse to rotate the tube to prevent invagination. It seems during one of the intervals between the rotations, a segment of the bowel wall had invaginated itself so extensively that strangulation with suggillation changes hud manifested itself; hence the ligation and excision. The primary operation was for removal of an appendix; the patient recovered after some fever and tenderness over the abdomen suggestive of local peritonitis. ]
"In one case of Dr. Waite's, the drain-tube happened to be a glass tube of Dr. Keith's. and we were obliged to break the tube to safelv liberate the gut-wall. Now, it appears to me that the hernia of the gut-wall in these tubal holes, is due to irregular action of the muscles in the gut wall. It is disordered peristalsis. The presence of the tube may irritate the muscles of the gut to act irregularly or in a disordered manner. It seems to me the same views can be applied in many cases of hernia. As the gut-wall approaches the small inguinal, femoral or the obturator cand it may become stimulated to irregular action just as it does around the hole in the drain-tube. In my opinion this explanation will account for the fact that the gut is found protruding through a very small aperture.

I have wondered almost as much how a loop of bowel could insinuate itself into such a small hole in the abdominal wall, as it could insinuate itself into a small round hole in my aluminum drain-tube. Keith's gluss drain-tube has unnecessarily large boles, and in many cases it is common to find omentum, appendix epiploicus, or bowel wull engaged and even strangulated through one or more of these holes. In my aluminum drain-tube I have specially made the side perforations small in order to avoid the liability to hernia. Hernia through a small hole in the abdominal wall is probably produced from irregular action of the gut-wull, just as' invagination is due to irregular muscular action of the bowel-wall.

". . The theory of irregular muscular action of the gut-wall as a cause of hernia I have never seen in literuture or heard it discussed; but it seems to me to offer an explanation of some very small tight herniæ.

"There is some cause at work producing hernia on the right side more than the left. There is almost double the amount of hernia on the right so far as inguinal is concerned. Also the right side preponderates in regard to both femoral and obturator."

\section{NOMENCLATURE.}

Intestinal wall herniæ are usually included under the term Littre's herniæ. Still it must be borne in mind that a Littre hernia may be either a true diverticular hernia or a partial intestinal wall hernia. Both of his cases were of the chronic form.

$\mathrm{His}$ second case ${ }^{3}$ was one of chronic partial enterocele, where a segment of the colon had become adherent and incarcerated at a ventral ring to the left and above the umbilicus.

Littre's first case ${ }^{10}$ was his famous case of a chronic congenital diverticular hernia, where a Meckel's diver. ticulum, in this case given off from the ileum, formed the contents of the hernial sac. which was engaged in the left inguinal ring and canal.

The other two forms of divertieula, viz., the normal appendix vermiformis and the anomalous appendix described by Rokitansky ${ }^{12}$ may also form the hernial contents, though the latter, seldom. These anomalous or false diverticula Rokitansky describes as follows:

"Such fulse divertieula consist only of mucous membrane and peritoneum, being herniæ of the intestinal mucous membrane resulting from the separation of the fibers of the muscular coat; they develop along the jejunum, the ileum and the large intestine, most often in large numbers (several hundred being met with in one case). They are pea to walnut sized, round, ponched; especially along the large intestine 
they develop into nipple-shaped diverticula, at times arranged together like a grape cluster. (Fig. 5.) In the small intestines they develop, as a rule, along the concave margin between the omental sheaths. These hernial bayings-out of the mucous membrane of the intestines may, through stagnation of feces, concretion development, etc., lead to peritonitis, which under certain conditions may simulate an incarceration with strangulation." An example, possibly, of such a Rokitansky* diverticular hernia with inflammatory and suppurative reaction is the very interesting case reported by Dr. J. B. Roberts, ${ }^{13}$ as follows:

Case 7-A woman, Polish, aged 28. Patient noticed, during the fifth month of her pregnancy, which was about a year before she came under my observation, that a swelling the size of a thimble appeared in her left groin. It varied in size at different times, and disappeared when the patient assumed the recumbent position. The enlargement persisted after the birth of her child and remained in its previous condition until two weeks before I saw her, when her bowels became very much constipated and she suffered from violent attacks of nausea and vomiting. From that time she had had no natural movement of the bowels, which had been moved only by the aid of rectal injections which had been ordered by a physician to be taken daily. For a week previous to the time this history was taken, there was no movement of the bowels whatever, not-

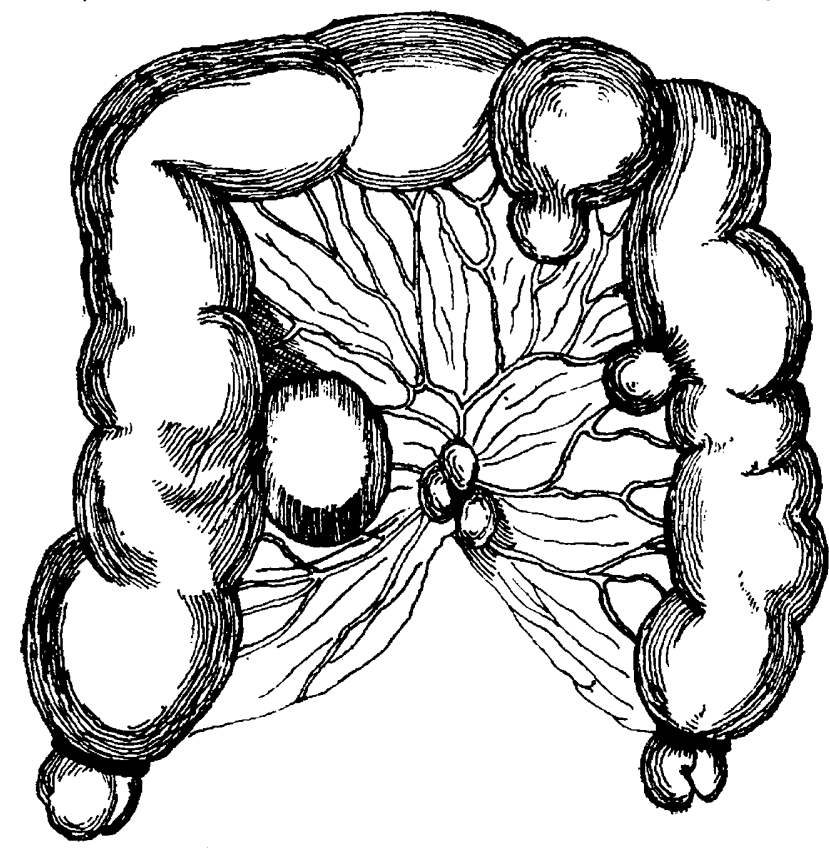

Fig. 5.-Showing position of development of false diverticula of the intestine.

withstanding enemata; before that acute constipation. An oblong swelling was observed in the groin in the region of Poupart's ligament. This was red and tender and looked very much like a suppurating bubo. The left labium was swollen and inflamed and was continuous with the inflamed mass in the left groin. Percussion gave tympanitic notes. At no time was there found any connection between the intestine and the swelling in the groin.

Operation.-An abscess cavity was entered and fetid gas and a large quantity of thin and extremely fetid pus escaped from the wound, together with broken down tissue and old clots of blood; irrigation. A rounded mass about the size of a small walnut was also washed from the wound. Its external surface consisted of a grayish tissue which when incised showed contents to be a dark, tarry granular substance of fecal odor. It was found that the abscess extended downward through the femoral canal in to the pelvis. No bowel or opening into the bowel was discovered. At the time of the operation I thought that an abscess had been formed by inflamma tory involvement of the tissues surrounding a strangulated Littre's hernia, which had become gangrenous, or that the

* Compare K. F. Riecke's theory " "Ueber Darmanhang Brüche," 1841) for the origin of acquired diverticula with explanations of illus trations 1 and $2 ;$ also with Rokitansky's description and the report of
Robert's case. tumor resulted from a pelvic abscess which had commenced with the bowel and permitted the entrance of fecal matter into the sac. The former supposition was proved to be the correct one by the pathologist's report.

Examination of the specimen, as made by Drs. Formad and Van Gasken, proved the rounded mass to be inspissated fecal matter and containing particles resembling tomato seed, pepper and other articles of food. The sac or membranous mass was found, on section, to be a portion of intestine. Other pieces of feces were washed away in the post-operation irrigation. The patient made a rapid recovery.

It is evident that the section of the circumference of the intestinal wall which was strangulated sloughed away, permit. ting masses of hardened feces to escape into the hernial sac and that the intestinal opening became closed.

Finally, the scybalous feces became surrounded, in one instance, with a sort of capsule; and then an abscess occurred around the fecal masses and a portion of the bowel which had been detached at the point of constriction when strangulation happened. (Med. News, Phil., 1893, vol. 63, p. 460.)

\section{CONCLUSIONS.}

1. Acute partial enterocele does occur.

2. The symptoms of an acute partial enterocele are of a milder type than those of an acute complete enterocele; when strangulated the vomiting is not stercoraceous, constipation not absolute. Exceptionally, the reaction is so slight, that the condition continues unrecognized.

3. Because of mildness of symptoms, smallness of size and its tendency to disappear, it requires most careful differentiation.

4. Acute partial enterocele is to be especially differentiated in its early form from an enlarged inguinal gland; in its later or inflammatory form from an adenitis suppurativa.

5 . The acute form of partial enterocele if not relieved, either induces the usual reactionary changes of an acute hernia, or it is converted gradually into the chronic form of partial enterocele.

6. Its treatment is reduction, per taxis or herniotomy.

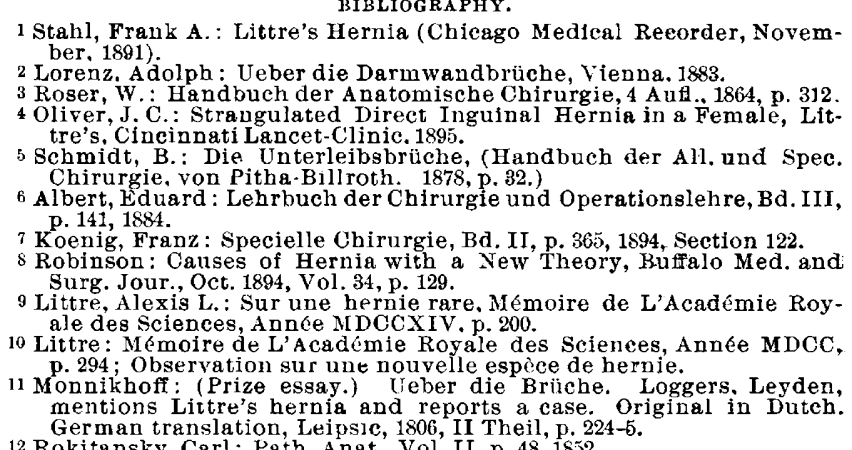

13 Roberts, J. B. : Strangulated Littre's hernia at the femoral ring, Medical News, Phila., 1893, Vol. 63, p. 460.

$$
\text { DISCUSSION. }
$$

Dr. Thomas H. Manley of New York-The question of the existence of a partial indirect hernia I do not think can be disputed. I have, within the last three months, seen a case in the father of a physician, which practically illustrates this unusual type. Dr. Stahl does not emphasize his point sufficiently. Reeder's hernia is undoubtedly due to a congenital diverticulum. The other is a simple bulging or escape of a part of the intestinal wall through an opening similar to what the Doctor has shown occurred in the patient of Dr. Robinson. There are a few cases which I am inclined to take issue with. I have done more than one hundred operations on strangulated herniæ and have never had one such as Reeder describes. In the event of a strangulated hernia, however, there is great danger to life because the lumen of the canal is free. If there is any instance in which $I$ can shut off with safety, it is in a Reeder's hernia. In a case of partially strangulated enterocele the important question is the great difficulty of diagnosis, and I would be inclined to agree with those who say that it would be very difficult to determine what the real difficulty was. I am sure 
that it is only with those dangers which attend mortification that we have to deal because with this imperfect hernia comes a tumor. The only case that I have met was an old man of 76 in whom there was a tumor the fourth day afterward. The symptoms of strangulation are not constant, but may approach shock. It is important to detect this in time, and 1 believe the condition referred to in the paper is much more common than is generally supposed.

Dr. Miles F. Porter of Indiana-I know that this condition does occur and occurs acutely, for I remember a case occurring in a female child twenty-two months old. The diagnosis was made and operation revealed a Littre's hernia with strangu lation.

Dr. G. G. Davis of Philadelphia-I remember an old lady about sixty years of age who was brought into the hospital after having suffered with symptoms of strangulated hernia for about ten days. I thought it was a Littre's hernia of a por tion of the intestinal wall, and in the diverticulum. On oper ation I found there was a cancerous body embracing one quarter of the circumference of the gut and about one inch long. This pointed definitely to the fact that a partial strang ulation of the gut itself occurred, and goes to show that the only history is one of length and not acute.

Dr. SMrTH-The fact that we have symptoms of strangulated hernia with the passage of gas has been proven. We sometime incline to err because the existing symptoms are not compatible with the conditions. It is important for every one to appre ciate the fact that whenever a hernia is strangulated it should either be reduced easily and promptly, or treated by operation. The danger from the operation is very much less than from the excessive use of taxis. Having this additional danger brought before us today, it is very likely to save many a patient from excessive taxis.

Dr. J. McFadden Gaston of Atlanta, Ga.-I saw four cases of this particular kind of hernia before I recognized the character of the trouble, and in three of them I succeeded in reduction by taxis. The evidence was very conclusive of the existence of the hernia. In one case I used taxis to a considerable extent, under anesthesia. After letting the patient rest, and using asefedita and belladonna. I was able to reduce it by taxis. I was called in consultation in another case in which we all agreed that it was a case of obstruction of the bowel of some form and we agreed that possibly it might be an indurated gland. The symptoms all pointed to bowel obstruction, however, and we treated upon this principle. The case went on to the point when there was an indication of liquid formation and fecal extravasation, death ensuing. I thought we would find a partial dislocation of the intestine, which was verified.

Dr. E. TAPPEY of Detroit, Mich.-As to the condition of the intestine in the first diagram that was shown, in a Littre's hernia, a portion of the intestinal wall becomes herniated and my conception is that there is necessarily a formation of an angle on the opposite wall of the hernia. I suppose that if the intestine gets into the position shown in the diagram, it must be that the hernia has become chronic and adhesions have formed. The intestine becomes distended, but I do not think that this condition can exist in an acute condition. I have seen this condition of Littre's hernia where a portion of the intestine had become herniated in the median line just below the diaphragm.

Dr. E. D. Ferguson of Troy-My observations in these cases have been where the hernial protrusion has been much drawn out of the usual sites. I wish to speak of one point in the management of the case. Usually when we have hernias of this kind and succeed in reducing them, we must take into consideration the extreme liability of adhesions in the intestinal cavity. The wisest surgical procedure would be to proceed at once to the obliteration of the hernia canal.

Dr. BurNs of Long Island City -1 have had one case with symptoms of intestinal obstruction, although it was not considered by the doctor in attendance that the hernia accounted for the symptoms. I was called in and examined all the points referring to the possibility of hernia. There did not seem to be enough of importance to warrant us in saying what it might be and we removed the patient to the hospital to operate on her. During the operation I opened a sac and introduced my finger to examine it when $I$ found that something had sunk back from the inguinal canal. I found the inguinal glands quite free. I concluded to close the canal and we decided not to explore with a further incision in this particular case. The symptoms became better after the operation and in ten days the patient left the hospital. I kept her on a suitable diet and there was some slight rise of temperature. We let her leave the hospital in a spring wagon, and she traveled about one and a half miles on a country road. Upon arriving home she ate a German dish and I was called to see her a few hours afterward, when she died suddenly. My personal conviction was that she had omental hernia, but I am now convinced that she had a hernia of the kind mentioned today. I was very sorry that an autopsy could not be secured. I remember another case of a similar nature in a very stout woman. I had no proper apparatus for operation but I concluded to operate. I succeeded in replacing it through the natural aperture and she was able toleave off her truss which she had been wearing for a long time.

Dr. HATCH of Quincy, Ill.-There is a class of cases which can be very easily mistaken for obstruction to the bowels. I mean the class where there is a partial incrustation of the in testine. In these cases you will find attachments around the coating of the intestines which simulate incrustations, and you will also find that, on the sides of the intestine, the feces are in batches, leaving but a small opening, so that you have all the symptoms of an obstruction and some of those of a hernia, with intense pain. Such was the case that $I$ saw, and I had one of the same kind about a month ago. By the application of warm fowentations and small repeated doses of calomel I was able to remove all but a few incrustations around the intestinal wall.

Dr. STAHL - So far as the meaning of a Littre's hernia is concerned, it is mentioned to a considerable extent in French literature. Our friend from Detroit tells us that he had a case above the umbilicus, and Littre's second case was just such a one. This was the chronic form, which my own case must have been. My own case was purely a case of intestinal wall bernia. Littre's first hernia was one of Meckel's ganglia. We have two appendices in poultry, and when we have a Meckel's ganglia it is a very similar thing. This is well shown by the mesentery in poultry. The American Text-Book shows that, in the treatment of a Littre's hernia, we must understand hernias of all the parts of the diverticulum, whether congenital or acquired. So far as the term is concerned we must still use it as he first described both the congenital and the acquired forms. There are other forms which I have not been able to bring out. The only object that I have in presenting this paper is to state what is not usually well known, that the whole intestinal wall is not drawn out. Whether the case is congentital or acquired is important, and hard to decide.

It is not an infrequent form of hernia. If we can prove that the acute form does occur we will then have broughi much credit upon our meeting.

\section{A NOVEL METHOD FOR THE USE OF DRY HEAT IN THE MIDDLE EAR DIS. \\ EASE, OTALGIA, ETC.}

Presented in the Section on Laryngology and Otology, at the Fortyeighth Annual Meeting of the American Medical Association, beld at Philadelphia. June 1-4, 1897.

BY E. LARUE VANSANT, M.D.

PHILA DELPHIA, PA.

The local use of dry heat has long been justly regarded as a valuable therapeutic agent in treating inflammations of the ear, otalgia, etc.; these applications in the form of hot salt and bran bags, or hot water bottles, however, are usually only made to the external ear, the actual amount of heat, therefore, coming in contact with the external auditory canal and membrana tympani is necessarily slight. It has often occurred to me, while treating various forms of ear diseases, that the direct application of heated dry air to the drumhead and middle ear would be desirable, provided we had an apparatus whereby the degree of heat could be regulated, and by the aid of which it could be readily obtained and applied. I have now such an apparatus, having found it to answer the desired purpose. It is a modification of an instrument which was first devised for the purpose of dental surgery. It consists of a metallic bulb or barrel containing a piece of carbon, a rubber hand-ball aircompresser, and a long curved pointed steel nozzle. The bulb (or barrel) is heated sufficiently by being held over a flame, preferably that of a spirit lamp; a current of air is then forced through it by means of the hand ball, thus delivering a small stream of heated 